\title{
AUTHOR INDEX \\ Volume 53
}

Acharyya, Rajat \& García-Alonso, María D. C., Parallel Imports, Innovations and National Welfare: The Role of the Sizes of Income Classes and National Markets for Health Care $1(2008) 57$

Afzal, Mohammad, Long-Run Relationship Between Imports and

Exports: Evidence from Asian Countries

2 (2008) 261

Aldrich, Daniel P., Location, Location, Location: Selecting Sites for Controversial Facilities

$1(2008) 145$

Arndt, Sven W., Production Networks and the Open Macroeconomy

3 (2008) 509

Athukorala, Prema-Chandra, Singapore and ASEAN in the New Regional Division of Labor

3 (2008) 479

Baldwin, Richard E., Managing the Noodle Bowl: The Fragility of East Asian Regionalism

3 (2008) 449

Bhatnagar, Ankur, see Seth, A. K.

2 (2008) 293

Blomqvist, Áke \& Qian, Jiwei, Health System Reform in China: An Assessment of Recent Trends

1 (2008) 5

Capuno, Joseph J., see Kraft, Aleli D.

1 (2008) 43

Chanda, Rupa, India and Services Outsourcing in Asia

3 (2008) 419

Dong, Weizhen, Cost Containment and Access to Care: The Shanghai Health Care Financing Model

1 (2008) 27

Fukuda, Shin-Ichi \& Ohno, Sanae, Post-Crisis Exchange Rate Regimes in ASEAN: A New Empirical Test Based on Intra-Daily Data

$2(2008) 191$

García-Alonso, María D. C. see Rajat, Acharyya

1 (2008) 57

Herberholz, Chantal, The Foreign Bank Effect on Value Creation in Commercial Banks Incorporated in Thailand

2 (2008) 215

Hillman, Arye L., Globalization and Social Justice

2 (2008) 173

Izumida, Nobuyuki, see Wataru, Suzuki

1 (2008) 121

Johdo, Wataru, Production Subsidy as a Macroeconomic Policy in a

Stagnation Economy

2 (2008) 317

Jones, Ronald W., Production Fragmentation and Outsourcing:

General Concerns

3 (2008) 347

Kirkegaard, Jacob F., Offshoring, Outsourcing and Production

Relocations - Labor Market Effects in the OECD and Developing Asia

3 (2008) 371 
Kiyota, Kozo, Matsuura, Toshiyuki \& Urata, Shujiro, Exchange Rate

Volatility and MNCs' Production and Distribution Networks: The Case of Japanese Manufacturing MNCs

3 (2008) 523

Kraft, Aleli D., Capuno, Joseph, Quimbo, J., Stella A. \& Tan, Jr., Carlos Antonio R., Information, Incentives and Practice Patterns: The Case of TB DOTS Services and Private Physicians in the Philippines

$1(2008) 43$

Lane, John \& Tsang, Sandro, Uncertainty in the Economics of Medical Decisions

$1(2008) 81$

Maliki, Health Card and Health Care Facilities Demand Among the Indonesian Elderly

$1(2008) 103$

Matsuura, Toshiyuki, see Kiyota, Kozo

3 (2008) 523

Mitra, Devashish \& Ranjan, Priya, The Economics of Offshoring: Theory and Evidence with Applications to Asia

$\mathrm{Ng}$, Kwan Kee, see Thangavelu, Shandre M.

3 (2008) 357

3 (2008) 539

Ogura, Seiritsu, see Suzuki, Wataru

1 (2008) 121

Ohno, Sanae, see Fukuda, Shin-Ichi

Qian, Jiwei, see Blomqvist, Áke

2 (2008) 191

1 (2008) 5

Quimbo, Stella A., see Kraft, Aleli D.

1 (2008) 43

Rana, Pradumna B., Trade Intensity and Business Cycle Synchronization: The Case of East Asian Countries

2 (2008) 279

Ranjan, Priya, see Mitra, Devashish

3 (2008) 357

Seth, A. K. \& Bhatnagar, Ankur, Influence of Demographic Variables on Indirect Tax Setting for Selected Indian States

Suzuki, Wataru, Ogura, Seiritsu \& Izumida, Nobuyuki, Burden of Family Care-Givers and the Rationing in the Long-Term Care Insurance Benefits of Japan

$1(2008) 121$

Tan, Jr., Carlos Antonio R., see Kraft, Aleli D.

1 (2008) 43

Tan, K. C., see Yip, Paul S. L.

2 (2008) 245

Thangavelu, Shandre M., Toh, Mun Heng \& Ng, Kwan Kee, Outsourcing and Fragmentation in Singapore's Manufacturing Industry

Toh, Mun Heng, see Thangavelu, Shandre M.

Tsang, Sandro, see Lane, John

Urata, Shujiro, see Kiyota, Kozo

3 (2008) 539

3 (2008) 539

1 (2008) 81

3 (2008) 523

Yip, Paul S. L. \& Tan, K. C., Impacts of Ageing Population on Monetary and Exchange Rate Management in Singapore

2 (2008) 245 